Heating.

\begin{tabular}{|c|c|c|c|c|c|}
\hline $\begin{array}{l}\text { Temp. of } \\
\text { NH,Cl. } \\
\text { Degrees. }\end{array}$ & $\begin{array}{c}\text { Rate. } \\
\text { De- } \\
\text { grees. }\end{array}$ & $\begin{array}{l}\text { Time. } \\
\text { Min- } \\
\text { utes. }\end{array}$ & $\begin{array}{l}\text { Temp. of } \\
\mathrm{NH}_{4} \mathrm{Cl}_{\text {l. }} \\
\text { Degrees. }\end{array}$ & $\begin{array}{c}\text { Rate. } \\
\text { De- } \\
\text { grees. }\end{array}$ & $\begin{array}{l}\text { Time. } \\
\text { Min- } \\
\text { utes. }\end{array}$ \\
\hline 170 & $\ldots$ & 0.0 & 185 & +1.0 & 12.8 \\
\hline 174 & +2.0 & 2.0 & I 86 & I. 4 & 13.5 \\
\hline 178 & 2.0 & 4.0 & 187 & $3 \cdot 3$ & 1 3.8 \\
\hline 180 & 2.0 & 5.0 & I 88 & 2.5 & 14.2 \\
\hline 182 & 2.0 & 6.0 & 190 & $3 \cdot 3$ & 14.8 \\
\hline 183 & 2.0 & 6.5 & I 94 & $2 \cdot 5$ & I 5.8 \\
\hline 184 & I.O & $7 \cdot 5$ & 200 & $2 \cdot 7$ & 18.0 \\
\hline 184 & $\neq 0.0$ & I I 8 & & . & \\
\hline
\end{tabular}

Cooling.

\begin{tabular}{|c|c|c|c|c|c|}
\hline $\begin{array}{l}\text { Temp of } \\
\text { NHiCl. } \\
\text { Degrees. }\end{array}$ & $\begin{array}{c}\text { Rate. } \\
\text { De- } \\
\text { grees. }\end{array}$ & $\begin{array}{l}\text { Time. } \\
\text { Min- } \\
\text { utes. }\end{array}$ & $\begin{array}{l}\text { Ter } \\
\text { NI } \\
\mathrm{De}\end{array}$ & $\begin{array}{l}\text { of Rate. } \\
\text { l. De- } \\
\text { s. grees. }\end{array}$ & $\begin{array}{l}\text { Time. } \\
\text { Min- } \\
\text { utes. }\end{array}$ \\
\hline 184.0 & & 0.0 & I 7 I & +2.0 & 7. \\
\hline 180.0 & -2.7 & I $\cdot 5$ & 172 & +1.2 & .8 \\
\hline 176.0 & 2.4 & 3.2 & 172 & \pm 0.0 & .2 \\
\hline 172.0 & 2.2 & 5.0 & I 7 I & -0.6 & 10.8 \\
\hline 171.0 & $3 \cdot 3$ & 5 & I & I. 4 & II. \\
\hline 170.0 & I. 4 & 6.0 & 16 & $3 \cdot 3$ & II .8 \\
\hline I 69.5 & 2.5 & 6.2 & I 68 & 5.0 & I 2 . \\
\hline 170.0 & I. O & 6.7 & I 64 & 4.0 & I \\
\hline
\end{tabular}

Transition occurs at $184^{\circ}$ and $17^{\circ}$ on heating and cooling, respectively. With the undried ammonium chloride determined at the same time, the transition occurs at $184^{\circ}$ and $r 73^{\circ}$.

\title{
Summary.
}

I. Ammonium chloride in the absence of water (dried 45 days at $5_{55^{-}}$ $165^{\circ}$ or 3 years at room temperature with phosphorus pentoxide in a high vacuum) undergoes transition at $184.5^{\circ}$, the same as the undried salt.

2. In the thermal measurement of transition points in a high vacuum, confusion may result from the greater thermal effects of distillation.

3. Wegscheider's explanations of the anomalous vapor density of dried ammonium chloride by a failure to undergo transition in the absence of water are untenable in the light of these results.

NEW YORK, N. Y.

[CONTrIbution from the Michigan College of Mines.]

\section{THE DECOMPOSITION OF STANNOUS CHLORIDE BY WATER AND BY POTASSIUM HYDROXIDE SOLUTIONS.}

By C. M. Carson.

Received September 12, 1919.

Introductory.

The experiments described in this paper were undertaken for the purpose of determining the composition of the precipitates formed when stannous chloride is decomposed by water. For, although the appearance of these precipitates is well known, no information concerning them is found in the literature with the exception of that contained in brief papers by Ditte, ${ }^{1}$ published 37 years ago. Ditte states that $\mathrm{SnCl}_{2}$.$2 \mathrm{H}_{2} \mathrm{O}$, when boiled with water, forms a hydrated oxychloride $\mathrm{SnCl}_{2} . \mathrm{SnO}$.$6 \mathrm{H}_{2} \mathrm{O}$; that this, when boiled with water to which stannous chloride is added, little by little, forms a crystalline basic salt, ${ }_{2} \mathrm{SnCl}_{2} \cdot 3 \mathrm{SnO} .6 \mathrm{H}_{2} \mathrm{O}$; and that the last named by further treatment with stannous chloride solution, yields a less basic precipitate, $\mathrm{SnCl}_{2} \cdot \mathrm{SnO} .4 \mathrm{H}_{2} \mathrm{O}$.

${ }^{1}$ Compt. rend., 94, 792, 864 (1882); Ann. chim., [5] 27, I45 (1882). 
Recently, an anhydrous basic stannous chloride has been described by Keller. This material was found enclosed in a tin object brought from an Indian mound in Florida, and had approximately the composition represented by $\mathrm{SnCl}_{2} . \mathrm{SnO}$. Preliminary analysis, by Keller, of an impure specimen of it gave $67 \%$ of tin and $13.6 \%$ of chlorine, while two analyses of more carefully selected samples gave:

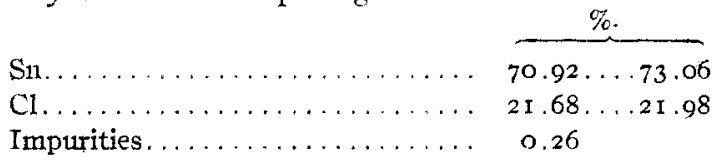

The present writer has prepared a crystalline basic salt with very nearly the atomic ratio given in Keller's preliminary analysis, but none with more than $17 \%$ of chlorine.

In the investigation of basic salts, the best guide is an application of the phase rule, first proposed by Miller and Kenrick. ${ }^{2}$ Thus, if several portions of a salt which forms basic salts with water, are treated with different proportions of water at the same temperature until equilibrium ensues, 3 cases may present themselves. ( $\mathrm{I}$ ) The precipitates, in a series of mixtures, are all of the same composition, but the solutions above them are different. These precipitates are a single chemical compound. (2) The precipitates in a series are all different, but the solutions are of the same composition. These precipitates are mixtures of two compounds in varying proportions. (3) The precipitates in a series are all different and the solutions are all different. These precipitates are solid solutions.

The rules which have just been stated apply to 2 component systems. The addition of potassium hydroxide to a system made up of stannous chloride, stannous oxide and water, introduces a fourth component. Now, while variable solutions indicate a bivariant system with 3 components, they may indicate either bivariant or tervariant systems with 4 components. It is still possible to apply the rules, however, under the following conditions, as stated by Miller and Kenrick: (a) The ratio of water to the other components must be large; $(b)$ the fourth component must not enter the precipitates; $(c)$ there must be a constant ratio between the fourth component and the water.

These conditions have been partly fulfilled in the experiments to be described, for when stannous chloride is treated with potassium hydroxide, the ratio of alkali to water is kept constant and the alkali does not enter the precipitate, but the ratio of water to salt is not large.

\section{Experimental.}

The stannous chloride used in the following experiments was prepared from Baker \& Adamson's C. P. salt. About $500 \mathrm{~g}$. at a time was treated

1 This Journal, 39, 2354 (1917).

${ }^{2}$ J. Phys. Chem., 7, 259 (1903). 
with tin and hydrochloric acid; the mixture was boiled gently until most of the free acid was removed and was then allowed to cool. The crystals which deposited were drained as thoroughly as possible and dried between filter papers. The product consisted of transparent, colorless crystals which dissolved in a small proportion of water, leaving no residue. The relative proportions of tin, chlorine and water in the lots of salt, prepared at different times, varied to some extent. It was found necessary, therefore, to make a batch of crystals sufficiently large for a complete series of experiments, in order that the results might be comparable.

The first series of experiments was carried out in the following way: A weighed quantity of the salt, usually $25 \mathrm{~g}$., was placed in a flask of from Ioo to I000 cc. capacity, and a measured volume of water which had been boiled vigorously for 20 minutes, to expel air, was added to it. The flask was connected to a reflux condenser, a current of nitrogen was passed through the apparatus and the mixture was boiled for 8 hours. The mixture was then filtered into a dry flask, and the precipitate and solution analyzed. The precipitates were not washed, as that would alter their compositions materially, but were dried between filter papers. Of course, the dried precipitates were contaminated with a small amount of mother liquor, but since they contained, in all cases a large amount of stannic salt, accurate knowledge of their composition would be useless. The results are given merely because the appearance of the white precipitates formed by the hydrolysis of stannous chloride is so well known.

The analysis of the solutions seemed to offer no difficulty, as they contained only stannous chloride and a small excess of hydrochloric acid. A measured volume of the mother liquor was pipetted into a weighing bottle, the weight taken and the liquid diluted in a flask. The tin was precipitated as stannous sulfide and weighed as stannic oxide. The results by this method are slightly high, but with proper precautions are consistent. The filtrate from the stannous sulfide was boiled to remove the hydrogen sulfide and was then titrated with standard sodium carbonate for the determination of total chloride.

Later experiments have shown that in the presence of even very small amounts of strong acids, stannous sulfide sometimes carries down considerable amounts of chloride, which is not removed by washing. It is possible then that the analyses of mother liquors may be inaccurate, though comparable among themselves.

The precipitates of basic chloride were ground and weighed and were first treated with $20 \mathrm{cc}$. of $N$ nitric acid. The acid was next neutralized by ammonium hydroxide, acetic acid was added in excess and the volume was made up to IOO cc. with water. The precipitates were only slightly soluble in cold acids but when hydrogen sulfide was passed through the mixtures, complete transformation into tin sulfide took place. The sul- 
fides were filtered and weighed as stannic oxide. The filtrates were boiled to remove hydrogen sulfide and were then precipitated by silver nitrate.

Determination of the tin in the basic precipitates was also made by the Lenssen-Baker method, in which the tin is titrated by iodine in conc. hydrochloric acid solution. By reduction with aluminum, the total tin was obtained, while without reduction the tin in the stannous condition was given.

In all cases where stannous chloride was boiled with water, the precipitates contained such a large amount of the stannic salt, usually about $1 / 3$ of the total, that it was impossible to decide to what extent stannous chloride is hydrolyzed. The presence of the stannic salt is probably due to the presence of about $0.5 \%$ of quadrivalent tin in the stannous chloride. The results of the first series of experiments are given in Table $I$.

TABLE I.

\begin{tabular}{|c|c|c|c|c|c|c|}
\hline \multirow{2}{*}{ Expt. } & \multirow{2}{*}{$\begin{array}{c}\mathrm{Wt} \text {. of } \\
\mathrm{SnCl}_{2.2 \mathrm{H}} \mathrm{O} \\
\mathrm{G} .\end{array}$} & \multirow{2}{*}{$\begin{array}{l}\text { Cc. of } \\
\text { water. }\end{array}$} & \multirow{2}{*}{$\begin{array}{l}\text { Atomic ratio } \\
\text { c1: Sn in } 100 \mathrm{cc} \text {. } \\
\text { of mother liquor. }\end{array}$} & \multicolumn{2}{|c|}{$\%$ in ppt. } & \multirow{2}{*}{$\begin{array}{l}\text { Atomic ratio } \\
\mathrm{Sn}: \mathrm{Cl} \text { in ppt }\end{array}$} \\
\hline & & & & Tin. & Chlorine. & \\
\hline $1 \ldots \ldots$ & 25 & 100 & $\frac{0.2020}{0.1006}=2.02$ & 70.99 & 12.00 & 1. 76 \\
\hline $2 \ldots \ldots$ & . 25 & 250 & $\frac{0.0854}{0.0423}=2.02$ & 72.09 & 10.97 & I, 96 \\
\hline $3 \ldots \ldots$ & . 25 & 500 & $\frac{0.0426}{0.0208}=2.05$ & 73.16 & 7.88 & 2.76 \\
\hline $4, \ldots \cdots$ & - 25 & 1000 & $\frac{0.0218}{0.0106}=2.05$ & $74 \cdot 13$ & $5 \cdot 36$ & 4.12 \\
\hline $5 \ldots \ldots$ & . I5 & 1000 & $\frac{0.0120}{0.0058}=2.07$ & $\cdots \cdots$ & $\cdots \cdots$ & $\cdots$ \\
\hline $6 \ldots \ldots$ & Io & 1000 & $\frac{0.0087}{0.0042}=2.08$ & $75.7 I$ & 4.59 & $4.9 \mathrm{I}$ \\
\hline $7 \ldots \ldots$ & 5 & 1000 & $\frac{0.0043}{0.0021}=2.08$ & Partly & & \\
\hline $8 \ldots \ldots$ & 2.5 & 1000 & $\frac{0.0021}{0.0008}=2.61$ & Mostl & & \\
\hline $9 \ldots \ldots$ & I.O & 1000 & $\frac{0.00082}{0.00023}=3.52$ & Mostl & & \\
\hline
\end{tabular}

The precipitates in the first 6 experiments of the series were pale yellow and amorphous. Although slightly gelatinous, they filtered well. It will be seen that there is a continuous variation in the composition of the precipitates, that is, they become progressively more basic as the ratio of water to stannous chloride in the original mixture, increases. While the precipitates become more basic, the solutions become more acid, but since the precipitates are small, ranging from 0.2 to $0.5 \mathrm{~g}$., the change in the composition of the solution is small.

When the weight of water in the original mixture becomes 200 times 
greater than the weight of salt, black crystalline stannous oxide is formed after boiling for two hours. The black crystals are mixed with some yellow precipitate, largely oxidized basic chloride. In Expts. 8 and 9, it will be observed that the solutions have become very acid, though this change might be expected in Expt. 7, where the black precipitate first appears.

The failure to distinguish basic compounds from mixtures was due to oxidation which might possibly be prevented by greater precautions, but as the desired information may be obtained by the use of potassium hydroxide solutions, the first method was abandoned. When stannous chloride is hydrolyzed by alkalies, the precipitates are not only much larger than when pure water is used, but they may also be separated from the relatively small quantity of stannic compound by decantation.

In the second series of experiments, the same ratio of stannous chloride and water was used as in the first series. The mixtures were boiled as before but, after the precipitates were filtered off, the mother liquors were preserved in corked flasks and allowed to cool overnight to $25^{\circ}$. These filtrates, with the exception of No. 3 , deposited white amorphous precipitates only, which were less basic than those formed at the boiling point, while the mother liquors became more acid. From No. 3, in which $25 \mathrm{~g}$. of salt was boiled with $500 \mathrm{cc}$. of water, a small amount of white amorphous precipitate was deposited, together with about $0.2 \mathrm{~g}$. of crystals. The crystals formed hexagonal rosets of about one mm. in diameter, and adhered tenaciously to the flask in which they were deposited. 'The rosets are made up of thin, transparent, colorless plates. Analysis of the crystalline material gave $73.63 \%$ of tin and $16.51 \%$ of chlorine or an atomic ratio, $\mathrm{Sn}: \mathrm{Cl}$, of $\mathrm{I} .33$, which could be represented by the formula

$$
{ }_{3} \mathrm{SnCl}_{2.5} \mathrm{Sn} .0 .3 \mathrm{H}_{2} \mathrm{O} \text {. }
$$

Analysis of the amorphous precipitate, deposited along with the crystals, showed an atomic ratio of 1.93 , but about $20 \%$ of the tin was in the stannic state while in the crystals the oxidation was only $0.6 \%$. The crystals were soluble in Ioo cc. of $0.3 \mathrm{~N}$ nitric acid. Washing the crystals with water, to free them from mother liquor, renders them slightly more basic, for it was shown that $0.2 \mathrm{~g}$. of the substance of atomic ratio $\mathrm{I} .33$, after being washed with four $20 \mathrm{cc}$. portions of water, had an atomic ratio of I. 35 .

The crystals mentioned in the preceding paragraph may be obtained in larger amounts by using stannous chloride which has been overheated during its preparation. By starting with a slightly basic salt prepared in this way, when $25 \mathrm{~g}$. was boiled with $500 \mathrm{cc}$. of water for one hour, and the mixture cooled, I.2 g. of crystals was deposited. From 0.25 to 0.5 g. of crystals was also deposited when $25 \mathrm{~g}$. of the same salt was treated in the same way with 250 or with $1000 \mathrm{cc}$. of water. 
Interaction of Stannous Chloride and Potassium Hydroxide Solutions.

The next series of experiments was carried out for the purpose of determining the effect of a fixed volume of potassium hydroxide solution of a certain concentration on different weights of stannous chloride. In each experiment roo cc. of $0.2 \mathrm{~N}$ potassium hydroxide solution was used, and the weight of the salt was varied from 3.5 to $75 \mathrm{~g}$. The mixture was put in a flask which was attached to a reflux condenser, the air was displaced by a current of nitrogen and the mixture was boiled for 6 hours.

When $100 \mathrm{cc}$. of $0.2 \mathrm{~N}$ potassium hydroxide solution is added to $25 \mathrm{~g}$. of stannous chloride, a pale yellow precipitate is thrown down. When the mixture has been boiled for a few minutes, however, this curdy precipitate suddenly changes to white crystals which become slightly yellow on continued boiling. The crystals settle rapidly and therefore may be washed by decantation with small amounts of water. This washing alters the composition of the crystals to some extent, but the results are probably more accurate than those which would be obtained by less direct methods.

When the volume of $0.2 \mathrm{~N}$ alkali is still $100 \mathrm{cc}$, but the weight of stannous chloride is between 3.5 and $5.5 \mathrm{~g}$., the precipitate is no longer crystalline. It settles rapidly, however, and may be washed, though not so readily, as in the case of the crystalline precipitate.

After the mixtures were boiled, they were filtered, part of the filtrate was pipetted off for analysis, while the remainder was allowed to cool in a corked flask. The precipitates were washed and then dried at $80^{\circ}$. The analyses were conducted as before.

The results of this series of experiments are given in Table II.

TABLE II.

roo cc. of $0.2 N$ Potassium Hydroxide Solution. Time of boiling, 6 hours.

\begin{tabular}{|c|c|c|c|c|c|}
\hline \multirow[b]{2}{*}{ Expt. } & \multirow{2}{*}{$\begin{array}{c}\text { Weight of } \\
\mathrm{SnCl}_{2} .2 \mathrm{H}_{2} \mathrm{O} \\
\text { G. }\end{array}$} & \multirow{2}{*}{$\begin{array}{l}\text { Atomic ratio } \\
\text { Cl: Sn in } 100 \\
\text { cc. of solution. }\end{array}$} & \multicolumn{2}{|c|}{$\%$ in crystals. } & \multirow{3}{*}{$\begin{array}{l}\text { Atomic ratio } \\
\text { Sn: } \mathrm{Cl} \text { in } \\
\text { crystals. } \\
\mathrm{SnO}\end{array}$} \\
\hline & & & Tin. & Chlorine. & \\
\hline $1 \ldots \ldots \ldots \ldots$ & 3.0 & alkaline & 87.6 & small & \\
\hline $2 \ldots \ldots \ldots \ldots$ & 3.5 & $\frac{0.00774}{0.00403}=1.92$ & 80.10 & 10.58 & 2.24 \\
\hline $3 \ldots \ldots \ldots \ldots$ & 4.0 & $\frac{0.0116}{0.0060}=x .93$ & 79.95 & 10.93 & 2.18 \\
\hline $4 \ldots \ldots \ldots \ldots$ & 5.0 & $\frac{0.0158}{0.0083}=1.91$ & 80.10 & II .07 & 2.17 \\
\hline $5 \ldots \ldots \ldots \ldots$ & 6.0 & $\frac{0.0272}{0.0143}=1.90$ & 73.76 & 15.90 & 1.38 \\
\hline $6 \ldots \ldots \ldots \ldots$ & 7.0 & $\ldots \ldots \ldots \ldots$ & 73.75 & 16.15 & $x .36$ \\
\hline $7 \ldots \ldots \ldots \ldots$ & 16.0 & $\frac{0.1045}{0.055^{\circ}}=1.91$ & 73.45 & 16.09 & 1.36 \\
\hline $8 \ldots$ & 25.0 & $\frac{0.1752}{0.0903}=1.94$ & 73.31 & 16.52 & I. 32 \\
\hline $9 \ldots \ldots \ldots \ldots$ & . 30.0 & $\ldots, \ldots \ldots \ldots$ & 73.41 & 16.55 & I. .30 \\
\hline
\end{tabular}


In Expt. 2, where $3.5 \mathrm{~g}$. of stannous chloride was used, there was a small amount of black stannous oxide crystals, from which the lighter yellowish precipitate was separated by decantation. It is evident, then, that the yellowish precipitate here obtained is the most basic of the basic stannous chlorides. Its composition is represented, approximately, by the formula ${ }_{2} \mathrm{SnCl}_{2} .7 \mathrm{Sn}(\mathrm{OH})_{2}$. There is a slight variation in the composition of the precipitates in Expts. 2, 3 and 4, though this could be expected on account of the difficulty in separating the precipitates from the mother liquors. But a very striking change takes place when the amount of salt is increased to $6 \mathrm{~g}$., as in Expt. 5. The precipitate becomes crystalline in character and much less basic than in Expt. 4. With increasing amounts of stannous chloride, the precipitate remains the same in appearance, but becomes somewhat less basic. When the amount of salt in the above series becomes greater than $30 \mathrm{~g}$. very little precipitate is formed. This is due to the presence in the stannous chloride of a small excess of acid, which uses up most of the potassium hydroxide. To the same cause may be attributed the differences in the precipitates of Expts. 5 to 9 . No attempt was made to neutralize the excess of acid in the original salt, but experiments were performed with from 40 to $75 \mathrm{~g}$. of stannous chloride and I00 cc. of $0.4 \mathrm{~N}$ potassium hydroxide solution." In these the crystalline precipitates were slightly more basic than in Expt. 9.

Indications of two compounds, in addition to the oxide, are given by the results in Table II, but the variations in the precipitates from Expts. 5 to 9 were so great that they must be regarded as mixtures. This view is strengthened by two facts: first, the precipitates do not dissolve completely in dil. nitric acid, but leave small, white residues, which are due to the presence of some of the stannic compound; second, the precipitates formed when the mother liquors of experiments such as No. 9 are allowed to cool, are pure white, and dissolve in dil. nitric acid without residue. They are higher in chlorine and lower in tin than the corresponding original precipitates, and always contain less of the stannic compound.

Thus, when $50 \mathrm{~g}$. of stannous chloride is boiled with Ioo cc. of $0.4 \mathrm{~N}$ potassium hydroxide solution and the hot mixture is filtered, the filtrate on cooling deposits about $2 \mathrm{~g}$. of the white crystals. Analysis of these crystals gave tin $72.82 \%$ and chlorine 16.93 , while analysis of the original crystals, formed in the boiling liquid, gave tin $73.41 \%$ and chlorine $16.23 \%$. The crystals deposited from the mother liquor, when $30 \mathrm{~g}$. of stannous chloride was treated with $100 \mathrm{cc}$. of $0.4 \mathrm{~N}$ potassium hydroxide solution, contained $73.11 \%$ of tin and $16.76 \%$ of chlorine, while the crystals formed in the boiling liquid contained $73.93 \%$ of tin and $16.11 \%$ of chlorine.

In all cases where the original precipitate formed at the boiling point 
was compared with the precipitate from the cooled mother liquor by titration with iodine, it was found that the first named contained from 0.5 to $1.0 \%$ of oxidized tin, while the precipitates from the mother liquors contained only from 0.2 to $0.5 \%$. This could only partly explain the higher chlorine content of the second crystals, even if it were assumed that the stannic compound had been completely hydrolyzed into the oxide. Other possible causes of difference are the adsorption of stannous chloride by the crystals as they separate from the mother liquor and failure ts remove this by washing; or the formation along with the first crystals of some of the more basic compound by local excess of alkali, and failure to transform this into the equilibrium compound. The washing caused some change in all of the precipitates, but probably about the same amount in all.

The crystals formed when $25 \mathrm{~g}$. of stannous chloride is boiled with 500 cc. of water and the mixture is allowed to cool, have already been described. They are somewhat higher in tin and lower in chlorine than the white crystals mentioned in the preceding paragraph. While in both cases the crystals are pseudo-hexagonal, in the case where pure water is used, the crystals always form rosets which are nearly spherical in shape. It might be supposed that the precipitate from the potassium hydroxide treatment contained potassium chloride which would decrease the tin and increase the chlorine content, but an analysis failed to show the presence of potassium.

An attempt was made to determine whether equilibrium had been reached in the preceding experiments, by utilizing the reverse reaction. Five g. of stannous oxide was boiled with $25 \mathrm{cc}$. of $1.96 \mathrm{~N}$ hydrochloric acid for 5 hours. The mixture was filtered and the crystals and mother liquor were analyzed. It was found that roo cc. of the mother liquor contained I.614 gram-atoms of chlorine and 0.827 of tin, a ratio of 1.95 ; while the crystalline precipitate contained $73.91 \%$ of tin and $16.13 \%$ of chlorine. That is, the precipitate is very nearly of the same composition as that of Expt. 7, Table II.

The solutions and precipitates obtained in this way are of the same character as those given by the treatment of stannous chloride with potassium hydroxide solution. But the experiment did not give definite proof that equilibrium had been established, since the mother liquor was much more concentrated than when potassium hydroxide was used.

\section{Summary.}

It seems definitely proved that a compound $2 \mathrm{SnCl}_{2}, 7 \mathrm{Sn}(\mathrm{OH})_{2}$ is the most basic of the basic stannous chlorides; that a slightly variable crystalline material, of approximately the formula ${ }_{3} \mathrm{SnCl}_{2} .5 \mathrm{SnO} .{ }_{3} \mathrm{H}_{2} \mathrm{O}$, is the precipitate commonly formed by the action of boiling solutions of potassium hydroxide on an excess of stannous chloride; and that there is no 
compound of intermediate composition. Whether any basic compound lies between ${ }_{3} \mathrm{SnCl}_{8} .5 \mathrm{SnO} .3 \mathrm{H}_{2} \mathrm{O}$ and the normal salt was not determined. The precipitates usually formed by the interaction of stannous chloride and water contain such a large proportion of stannic compound that the analyses are of no value in ascertaining the composition of the basic stannous chlorides.

In conclusion, I wish to express my indebtedness to Prof. Lash Miller, of the University of Toronto, who suggested this problem some years ago, and gave me considerable help with it.

Hovgrton, Mich.

[CONTRIBUTION FROM THE KENT Chemical LABORATORY OF THE UNIVERSITY OF CHICAGO.]

\section{THE EFFECTS OF ACIDS AND BASES ON THE SURFACE ENERGY RELATIONS OF $\beta, \beta$-DICHLOROETHYL- SULFIDE ("MUSTARD GAS"). ${ }^{1}$ \\ By William D. Harkins and D. T. EwING. \\ Received September 20, 1919.}

This investigation was undertaken in order to determine the relative efficiencies of various substances in the emulsification of $\beta, \beta$-dichloroethylsulfide in water, and with the idea that the results obtained would be of importance in connection with a study of its physiological action. The importance of the effects of acids and bases on interfacial tension has been pointed out by Haber and Klemenciewicz. ${ }^{2}$ An active part of a muscle is always electrically negative toward the part at rest, and the active muscle is acid in reaction while the resting muscle is slightly alkaline. An acid reaction always causes the phase which corresponds with the water at the water-benzene interface, to become negative, and in the muscle this aqueous phase is represented by the sarcoplasma in which the sarcostyles are imbedded. An interface of this nature acts as a hydrogen electrode, and it would seem probable that in addition to the change of electromotive force at the phase boundary, there should also be a change of surface tension near the neutral point with reference to the change from an acid to a basic reaction. The investigation which is commonly cited to show that laboratory experiments on simple twophase systems seem to confirm this point of view, is that of von Lerch, ${ }^{3}$ who, while working under Nernst's direction, found that the presence of sodium hydroxide at a concentration of $0.027 \mathrm{~N}$ in the aqueous phase, caused an extremely great lowering of the interfacial tension at the water-benzene phase boundary, a lowering amounting to $36 \%$. At the request of Pro-

${ }^{1}$ An investigation undertaken at the request of the National Research Council, and suggested to them by Lieutenant Colonel A. B. Lamb and Major R. E. Wilson.

${ }^{2} Z$. physik. Chem., 76, 385-43 I (1909).

${ }^{3}$ Drude's Ann., 9, 432 (1902). 